\title{
EL SERVICIO DE LA CULTURA COMO DEBER Y ATRIBUCIÓN ESENCIAL DEL ESTADO
}

\author{
JAVIER TAJADURA TEJADA \\ Profesor Titular de Derecho Constitucional \\ Universidad del País Vasco
}




\section{SUMARIO}

1. Introducción. 2. Constitución Y Cultura. 3. El derecho de acceso a la cultura (artículo 44 de la Constitución Española). 4. La función cultural del Estado (el artículo 149.2 de la Constitución Española). 5. Conclusión. 


\title{
EL SERVICIO DE LA CULTURA COMO DEBER Y ATRIBUCIÓN ESENCIAL DEL ESTADO
}

\author{
POR \\ JAVIER TAJADURA TEJADA \\ Profesor Titular de Derecho Constitucional \\ Universidad del País Vasco
}

«Esta es precisamente la función y la misión del Estado, el facilitar y ayudar a conseguir los grandes progresos culturales de la sociedad. Esta es su vocación. Para eso existe; para eso sirvió siempre y seguirá sirviendo".

F. LASALLLE.

\section{INTRODUCCIÓN}

El tema objeto de este trabajo, la función cultural del Estado, se ubica en lo que desde Jellinek se denomina "Teoría de los fines del Estado" y así ha sido abordado históricamente por los grandes tratadistas de la Teoria del Estado. Resulta en este sentido sumamente revelador cómo $\mathrm{H}$. Heller en su conocida Teoría del Estado destacó la nueva misión cultural del Estado en los siguientes términos:

"(...) su prestigio político (el del Estado) crece si se logra que el tipo de cultura representado por él sea adoptado como modelo para la formación de la vida. Las mismas formas del lenguaje, la literatura, la música y las artes plásticas, pueden, en determinadas circunstancias, obrar eficazmente en provecho del poder político. Por eso concede tanta importancia el Estado moderno a la política cultural en el 
interior y a la propaganda cultural en el exterior. Ningún Estado puede renunciar a la utilización de los poderes espirituales para sus fines"'.

Ubicado así el tema en tan amplio contexto las páginas que siguen pretenden mostrar la recepción constitucional del fenómeno cultural y en particular la llevada a cabo por el constituyente español de 1978 que ha asumido con claridad y rotundidad esa función cultural del Estado de la que hablaran Carré de Malberg y Heller, entre otros, al considerar uel servicio de la cultura como un deber y atribución esencial del Estado" (artículo 149.2 de la Constitución española).

\section{CONSTITUCIÓN Y CULTURA}

La irrupción de la cultura en el constitucionalismo es relativamente tardía. Por lo que respecta a nuestro país, ni una sola de las Constituciones españolas del siglo XIX incluyeron en su articulado la voz cultura. Cierto es que los textos constitucionales regularon materias conexas como la educación, la imprenta o la lengua, pero nunca hablaron expresamente de cultura.

Esta ausencia de la cultura en nuestras constituciones decimonónicas se dio también en el ámbito del constitucionalismo comparado. La recepción constitucional de la cultura tuvo que esperar hasta el siglo XX (Constituciones de Querétaro y Weimar).

En España, fue la Constitución republicana la que introdujo la cultura en el sistema constitucional. "Familia, economía y cultura" era el encabezamiento del capítulo II del Título III de dicho texto. A las "características culturales" de las regiones se refería el artículo 11. Y los artículos 48 y 50 aludían respectivamente al "servicio de la cultura" y a la "expansión cultural de España". De hecho, el tema cultural recibió un tratamiento apasionado en las Cortes Constituyentes, debido a la fuerte polémica que suscitó el debate sobre la «unidad cultural de España».

Ulteriormente, todas las constituciones europeas posteriores a la Segunda guerra mundial han constitucionalizado la cultura².

1 Heller, H.: Teoría del Estado, FCE, Mexico, 1971, págs. 225-226. (cursivas mías).

2 Según Prieto de Pedro, las constituciones portuguesa de 1976 y española de 1978 son wel modelo de la redacción más exhaustiva, sistemática y compleja que sobre dicho tema se ha realizado en un texto constitucional", en "Consideraciones sobre la enseñanza en la Constitución", Lecturas sobre la Constitución, UNED, Madrid, 1978. Tomo II, pág. 505. 
Nuestra Constitución de 1978 no es, en este aspecto, una excepción. Son numerosos los preceptos del texto constitucional que recogen el sustantivo "cultura" y el adjetivo "cultural»: Preámbulo, arts. 9.2, 25.2, 44, 46, 48, 50, 143.1, 148.1.17, 149.1.28 y 149.2. En otros muchos, $(3,20,27 \ldots)$ aparecen palabras cuya conexión con la noción de cultura es evidente: archivos, arte, artesanía, bibliotecas, ciencia, conservatorios de música, educación, investigación, lenguas, literatura, museos, patrimonio histórico-artistico, patrimonio monumental, técnica, tradiciones.

La profusión de preceptos que hacen referencia a lo cultural ha llevado a la doctrina a estudiar nuestra "Constitución cultural ${ }^{3}$ " y a considerar la posible calificación de España como "Estado de Cultura".

3 La expresión "Constitución cultural" es utilizada con frecuencia por los autores italianos. Pizzorruso define el concepto con gran amplitud: "Al lado del conjunto de principios que la Constitución dedica a las relaciones económicas deben situarse una serie de disposiciones de no menos trascendencia encaminadas a asegurar una protección básica a la vida humana considerada como valor en sí, al margen del uso que se haga de los recursos humanos en atención a fines políticos o económicos. Se da así entrada a una nueva dimensión de las garantías constitucionales cuyo núcleo esencial se halla en la protección de la libertad personal y de los demás derechos fundamentales vinculados de diversa manera a la misma y que se manifiesta, ante todo, en un conjunto de reglas generales tendentes a crear una situación ambiental que facilite lo más posible el ejercicio de las libertades individuales. En tanto que estas reglas generales, así como el principio de garantía de la persona y sus diversas especificaciones, encuentra su fundamento en una serie de opciones en las que se acepta un determinado modelo de cultura $-y$ un consiguiente rechazo de otros modelos contrapuestos- parece oportuno integrar toda esta temática bajo la noción común de constitución cultural, destacando bajo esta rúbrica una dimensión distinta de la definida como constitución económica, por más que los nexos e interferencias entre una y otra problemática no sean en modo alguno infrecuentes". Pizzorusso, A. Lecciones de Derecho constitucional, traducción de J. Jiménez Campo, CEC., Madrid, 1984. Vol. I, pág. 193. En nuestro país en los últimos años se aprecia también un creciente uso de tal expresión por la doctrina. Torres del Moral al comentar el artículo 44 de nuestra Constitución escribe: "Generalmente, podriamos decir que en todo texto fundamental, al menos en el constitucionalismo más reciente, coexisten una Constitución política, una Constitución económica y una Constitución cultural. Tal sucede en la Constitución española». Torres del Moral, A. "Comentario al artículo 44 de la Constitución" en Comentarios a las leyes políticas dirigidos por Oscar Alzaga, Edersa, Madrid, 1984. Tomo IV, pág. 210. También en Principios de Derecho constitucional español. Tercera edición, Madrid, 1992. Vol. I, pág. 88. La aparición del elemento cultural en el constitucionalismo más reciente, la existencia de una constitución cultural pone de manifiesto, según Prieto de Pedro, "una reciente sensibilidad, un énfasis nuevo en la valoración de este tema, un intento de aprehender jurídicamente la plenitud y la glo- 
La Constitución cultural viene definida por la interpretación sistemática de todos los preceptos que se refieren a la realidad pluridimensional en que la cultura consiste. Realidad pluridimensional porque en la Constitución la cultura presenta una triple faceta:

a) En primer lugar, la cultura es un ámbito de la vida humana, como lo es el político, el económico o el social. Tal es el sentido del párrafo quinto del Preámbulo constitucional al aludir a las dos dimensiones del progreso: la económica y la cultural. Dicha perspectiva se encuentra reflejada, de forma general, en el artículo 9.2 que atribuye a los poderes públicos la tarea de facilitar la participación ciudadana en la vida política, económica, cultural y social. El artículo 48 proyecta el principio a un sector social determinado: la juventud.

b) En segundo lugar, la cultura es un derecho. Ello se refleja en el artículo 44 de la Constitución. También en el artículo 25.2 en relación con los presos y en el artículo 50 referido a la tercera edad.

c) Por último, la cultura es una función del Estado como se desprende claramente del importantísimo artículo 149.2, consecuencia lógica de lo anterior. A la función protectora de las "culturas" y promotora de la "cultura" alude tambien el Preámbulo constitucional. Para su cumplimiento el Estado cuenta con una notable variedad de instrumentos: artículos 20, 27, $43.3,45,46,51.2$.

balidad de su concepto metajurídico, desbordándose el estrecho horizonte constitucional previo, que se circunscribía a considerar en lo cultural la instrucción pública y, en parte, la libertad de imprenta y poco más». Prieto de Pedro, J. Cultura, culturas y Constitución, CEC, Madrid, 1992, pág. 204. Además de la excelente monografía del profesor Prieto resulta imprescindible la obra de VAquer, M.: Estado y Cultura: la función cultural de los poderes públicos en la Constitución española, CERA, Madrid, 1998. Sobre la Constitución cultural, TAJAdura, J.: "La Constitución cultural» en Revista de Derecho Político, n. 43, 1998 y Ruiz Robledo, A.: "La Constitución cultural" en La Ley n. 4751, 10 de marzo de 1999. Aluden también a la "Constitución cultural", entre otros, BASSOLS COMA, M. "El patrimonio histórico español: aspectos de su régimen jurídico". Revista de Administración Pública, n. ${ }^{9}$ 114, 1987, pág. 94. Fossas, E. Regions i sector cultural a Europa. Estudi comparat: Bélgica, Franca, Itàlia i Espanya, Institut d'Estudis Autònomics, Generalitat de Catalunya, Barcelona, 1990, pág. 19. Pérez Moreno, A. en el “Prólogo" al libro de BARRERo Rodríguez, C. La ordenación jurídica del patrimonio histórico, Civitas, Instituto García Oviedo, Madrid, 1990, pág. 19. 
Respecto a la expresión Estado de Cultura ${ }^{4}$, hay que destacar que si bien no se halla expresamente recogida en el texto constitucional el amplio contenido cultural del mismo nos permite afirmar que España se constituye en un Estado de Cultura ${ }^{5}$.

La asunción del progreso de la cultura como fin estatal es lo que diferencia a un Estado de Cultura de otro que no lo es. Tal asunción se verifica en nuestro Texto constitucional desde el mismo Preámbulo que considera objetivo básico del constituyente fomentar el progreso de la cultura y se concreta en la claúsula del artículo 149.2 que veremos después. Este principio exige una acción positiva del Estado para hacer accesibles a todos los ciudadanos los bienes culturales. A lo largo del texto constitucional encontramos numerosos preceptos en que se atribuyen a los poderes públicos tareas en orden al desarrollo de la Cultura:

4 El origen de la expresión "Estado de Cultura» se sitúa en 1806 en la obra de Fichte "Die Grudzüge des gegenwärtigen Zeitalters". El pensador alemán empleó la expresión en un sentido muy amplio. Estados de cultura eran los Estados europeos occidentales surgidos en tiempo del cristianismo. La expresión adquiere sentido jurídico a partir de Bluntschli quien en su trabajo "Allgemeines Staatsrecht" publicado en 1852 clasifica a los Estados en Monarquías, Repúblicas o Estados de Cultura. "Los intereses culturales pueden determinar de forma especial la vida de un pueblo y es entonces cuando surgen los Estados de Cultura". Jung, $O$. Zum Kulturstaatsbegriff, Verlag Anton Hain. Meisenheim am Glan, 1976, págs. $10-$ 30. Tomo la cita de Prieto de Pedro, J. Cultura... ob. cit., pág. 213. La recepción constitucional de la expresión "Estado de Cultura» tuvo lugar también en Alemania un siglo más tarde. El artículo 3 de la Constitución del Estado de Baviera, de 1946, estableció: "Baviera es un Estado de Derecho, de Cultura y social que sirve al bien común".

5 En España, la idea aparece ya en la obra de Legaz Lacambra, que lo concibe como «un Estado que se subrogaría a la Iglesia como educador del pueblo y defensor de la moralidad" en "Estado de Derecho", Revista de Administración Pública, n. 6, 1951, págs. 17 y ss. A partir de la Constitución de 1978, se advierte también una creciente presencia de la expresión "Estado de Cultura» en la literatura jurídica Lucas Verdu, P. Curso de Derecho Político, Tecnos, Madrid, 1984. Vol IV, pág. 356. Torres del Moral, A. dedica un capítulo de su manual Principios de Derecho constitucional español al Estado de Cultura. Principios... ob. cit., pág. 86. El sintagma que nos ocupa ha llegado incluso hasta la jurisprudencia del Tribunal Constitucional de la mano de un voto particular a la sentencia de 13 de febrero de 1981 (F. j. 11): "Con ella el Estado, en cuanto Estado de Cultura, trata de garantizar el libre cultivo de la ciencia y su libre transmisión por via docente en todos los grados e instituciones del sistema educativo...". También GÁLVEZ, J: "Al asumir los poderes públicos la difusión de la Cultura, su desarrollo tiene que pasar a constituir una de las finalidades del Estado". GÁlvez, J. "Comentario al artículo 44 " en Comentarios a la Constitución, (Garrido Falla, F. dir.) Civitas, 2." ed., Madrid, 1985, pág. 803. 
a) Según el artículo 44.1. deben tutelar y promover el acceso a la cultura.

b) De los artículos 27.4 y 9 se desprende que han de garantizar la gratuidad de la enseñanza. A los poderes públicos compete la programación general de la enseñanza, con la participación de los sectores afectados -el principio democrático modula así el cultural-y la creación de centros docentes (art. 27.5), así como la vigilancia de todo el sistema educativo para garantizar que se cumplen las leyes (art. 27.8).

c) El Estado, en virtud del artículo 44.2, ha de promover el desarrollo de la investigación y la ciencia en beneficio del interés general.

d) El artículo 46 atribuye a los poderes públicos el deber de garantizar la conservación y promover el enriquecimiento del patrimonio cultural.

e) Otros muchos artículos contienen también obligaciones específicas del Estado en relación con lo cultural: artículos 25, 43.3, 50 y 51.

\section{EL DERECHO DE ACCESO A LA CULTURA (ARTÍCULO 44 DE LA CONSTITUCIÓN ESPAÑOLA)}

El artículo 44 de la Constitución de 1978 merece especial atención. Dicho precepto establece: "Los poderes públicos promoverán y tutelarán el acceso a la cultura, a la que todos tienen derecho". Disposiciones de este tenor son muy escasas en el Derecho constitucional comparado. Lo corriente en los textos constitucionales de nuestro entorno es emplear la expresión "derechos culturales". El antecedente de nuestro artículo 44 lo encontramos en la Constitución portuguesa de 1976 que dispone en su artículo 73.1: "Todos tienen derecho a la educación y a la cultura".

Como causas que explican la reticencia a reconocer el "derecho a la cultura" cabe señalar las siguientes ${ }^{6}$ :

a) La inseguridad del legislador ante la noción misma de cultura.

b) El temor a que de la cultura se derive una incontrolable demanda social de prestaciones.

6 Prieto de Pedro, J. Cultura... ob. cit., pág. 280. 
c) Restos de un pudoroso recelo, heredado del viejo Estado liberal, a considerar la cultura como objeto de prestación de los poderes públicos.

Los constituyentes españoles y portugueses dan un paso decisivo al consolidar la cultura como un derecho autónomo, en concreto como un derecho de prestación 7 .

En el caso español, la ubicación constitucional del «derecho a la cultura" en el capítulo tercero del título I, "De los principios rectores de la política social y económica», implica que las garantías del mismo son las previstas en el artículo 53.3 de la Constitución: vinculación finalista de la actividad de los poderes públicos, aunque sin posibilidad de ser exigidos de forma directa ante los Jueces y Tribunales.

Una concreta especificación del derecho a la cultura, el derecho a la educación, que también se configura como derecho de prestación, se halla en capítulo aparte. Ello obedece a la voluntad del constituyente de otorgar al derecho a la educación las máximas garantías constitucionales. El artículo 27 goza de la máxima protección que ofrece el artículo 53.2. "A pesar de una historia no excesivamente brillante en nuestros textos constitucionales -escribe Lopez Guerra- y en la práctica gubernamental, el derecho a la educación básica se configura hoy como un derecho subjetivo accionable inmediatamente, siendo el Estado responsable de su satisfacción, en forma directa (centros públicos) o indirecta (subvenciones a centros privados), según la modalidad que la ley parlamentaria escoja ${ }^{8}$ ".

El artículo 44 permite, pues, una visión plena, totalizadora, global del hecho cultural. Como señala Torres del Moral, el artículo 44 contiene uun concepto complejo y rico de cultura como cultivo del hombre en su más variada exigencia, como desarrollo de todas sus aptitudes, de todas sus capacidades; es la paideia de los griegos, la humanitas de los romanos, la civilitas del hombre medieval ${ }^{9}{ }^{\prime}$. En el mismo sentido, escribe Prieto de Pedro, "en el artículo 44 es donde la mención a la cultura despliega toda su plenitud semántica: en tanto condensa la dimensión público-subjetiva de los ciudadanos ante los poderes públicos en

7 «El derecho a la cultura es un derecho social en todo el sentido de la expresión. Quiérese decir con ello, no sólo que la cultura sea un bien social, sino que además tiene una proyección netamente social». GÁlVEZ, J. Comentario... ob. cit., pág. 803.

8 López Guerra, L. "Las dimensiones del estado social de Derecho" en Sistema. n. $38-39,1980$, pág. 181.

9 Torres del Moral, Comentario al artículo 44... ob. cit., pág. 210. 
las posibles exigencias de acceso a las manifestaciones de la cultura, cumple una función globalizadora, de síntesis, de la totalidad de los contenidos comprendidos en la noción étnica de cultura, como derecho a la diferencia, y en la noción general de cultura, como facultad de acceder a los bienes del espíritu que esta noción incluye ${ }^{10}$ ".

De la literalidad del precepto se desprende que el objeto del derecho constitucional recogido en el artículo 44 no es tanto el derecho a la cultura, como el derecho de acceso a ella. Como advierte Torres del Moral ${ }^{11}$, el derecho a la cultura es el derecho a los medios que faciliten su acceso; y como, por una parte, esos medios no son de producción y conservación espontánea, y por otra, dicho acceso no es abierto y libre, igualmente natural $y$ económicamente factible sino que queda reservado a unos pocos, el derecho a la cultura se convierte en el derecho a un servicio público. Enlazamos así con el tema de la función cultural del Estado.

\section{LA FUNCIÓN CULTURAL DEL ESTADO (EL ARTÍCULO 149.2 DE LA CONSTITUCIÓN ESPAÑOLA)}

Como señala Gálvez, el acceso a la cultura al que todos tienen derecho, tendrá que promoverse fundamentalmente partiendo de la organización y puesta en funcionamiento de los "servicios públicos culturales ${ }^{12 n}$.

La existencia de dichos servicios es la lógica consecuencia de la nueva configuración del Estado tras la segunda postguerra mundial y de la incidencia de ésta en su política cultural. Incidencia que siguiendo a Vaquer podemos afirmar que presenta una triple dimensión puesto que afecta a los instrumentos, a los ámbitos y a los fines de dicha política: "En primer lugar, se ha pasado - utilizando una conocida distinción de Forsthoff- de la "constitución" a la "acción" cultural, es decir, del mero diseño de un orden para la acción a la normalización de la acción en sí misma por parte del Estado. En segundo lugar, el Estado Social ha supuesto la universalización de los ámbitos de intervención estatal que, de reducirse prácticamente a la instrucción pública y la conservación del patrimonio histórico, han pasado a abarcar la generalidad de lo que conocemos como cultura. Y, en tercer lugar, este nuevo Estado se ha propuesto, más allá de la garantía formal de la libertad

10 Prieto de Pedro, J. Cultura... ob. cit., pág. 281.

1 Torres del Moral, A. Comentario... ob. cit., pág. 214.

12 Gálvez, J. Comentario... ob. cit., pág. 804. 
y la igualdad, promover positivamente su efectividad en el acceso de todos a los bienes culturales»" ${ }^{13}$.

La mera garantía de la libertad cultural no asegura el acceso de todos a la cultura. Los poderes públicos han de adoptar medidas positivas de desarrollo, a fin de hacer accesibles a todos los bienes culturales. ¿Quién garantizaría la conservación del patrimonio cultural si el poder público no asumiera dicha función? ¿Estaría igualmente asegurada la educación de todos los ciudadanos en condiciones de igualdad, si el Estado no la concibiera como un servicio público?

La aparición de los "servicios públicos culturales" es la lógica consecuencia de haber asumido el Estado como función, el desarrollo de la cultura, el progreso de la cultura, según la expresión del Preámbulo de la Constitución. Y haberlo asumido no como una función más, sino como "deber y atribución esencial» según la fórmula empleada por el artículo 149.2 de la Constitución, verdadera claúsula de constitucionalización del Estado de Cultura que dice así: "Sin perjuicio de las competencias que podrán asumir las Comunidades Autónomas, el Estado considerará el servicio de la cultura como deber y atribución esencial y facilitará la comunicación cultural entre las Comunidades Autónomas, de acuerdo con ellas". La fórmula nos recuerda a la empleada por la Constitución republicana en su artículo 48: "El servicio de la cultura es atribución esencial del Estado".

Vemos pues que nuestro ordenamiento constitucional recoge con toda claridad lo que podemos denominar un principio de intervención estatal en materia de cultura (artículos 9.2, 27.5, 44, 46, 48, 50 y 149.2). La Constitución obliga a los poderes públicos (a todos, centrales y territoriales) a realizar una labor activa en la vida cultural para lograr que todos los ciudadanos tengan acceso a los bienes culturales. $Y$ partiendo de este dato indiscutible es como hay que analizar la relación de ese principio constitucional con otro principio fundamental como es el principio de libertad cultural. En este sentido Ruiz Robledo ha advertido como "la tensión entre los principios de neutralidad y de intervención en la cultura del Estado es un epifenómeno de la tensión que se produce entre el Estado de Derecho, garantizador de unas libertades públicas (gracias fundamentalmente a su abstencionismo), y el Estado Social, defensor de los sectores sociales más frágiles mediante una política activa e intervencionista» ${ }^{14}$.

13 Vaquer Caballeria, M.: Estado y Cultura... ob. cit., pág. 64.

14 Ruiz Robledo, A.: "La Constitución... ob. cit., págs. 3-4. 
La participación de una persona en la vida cultural puede ser activa, como creador de bienes culturales, o pasiva como receptor de los mismos. De esta dualidad se deduce que la obligación de los poderes públicos en materia cultural es doble: por un lado han de procurar que ninguna persona capaz e interesada deje de incorporarse al reducido círculo de creadores culturales; por otro lado han de velar por que todas las personas puedan disfrutar del mayor número de bienes culturales posibles. El Estado, por tanto debe promocionar tanto la creación como la difusión de la cultura, pero sin cercenar la libertad cultural. ¿Cómo alcanzar el necesario equilibrio entre ambos principios: libertad cultural y promoción de la cultura? Ruiz Robledo responde a este interrogante con palabras que compartimos plenamente: "el equilibrio debe estar en algún punto medio entre el abstencionismo total de ni siquiera subvencionar económicamente las actividades culturales privadas (se vulneraría el principio de promoción) y el dirigismo avasallador de controlar cualquier iniciativa particular (se vulneraria el de libertad cultural)" ${ }^{15}$. En un principio puede parecer que desde un punto de vista jurídico esta respuesta es en exceso imprecisa e indeterminada. Sin embargo proyectada sobre los problemas juridico-políticos que sobre el tema se plantean tiene una enorme virtualidad y es precisamente la de excluir esas posturas extremas.

En cualquier caso es preciso dejar bien ćlaro que los poderes públicos no sólo pueden fomentar la cultura mediante la fórmula habitual de subvencionar las iniciativas particulares, sino que pueden ellos mismos organizar las actividades culturales que estimen convenientes. El Tribunal Constitucional ha confirmado esta tesis referida al ámbito del fomento de la Ciencia: "No resulta en absoluto convincente -afirma el Alto Tribunal- la tesis de que el fomento de la investigación científica y técnica, dado su contenido, circunscriba la competencia estatal, y en su caso, la autonómica, al mero apoyo, estímulo o incentivo de las actividades investigadoras privadas a través de la previsión y otorgamiento de ayudas económicas o de recompensas honoríficas y similares, excluyendo como contrapuestas aquellas otras acciones directas de intervención consistentes en la creación y dotación de centros $y$ organismos públicos en los que se realicen actividades investigadoras, sino que la señalada expresión engloba a todas aquellas medidas encauzadas a la promoción y avance de la investigación, entre las que, sin duda, deben también incluirse las de carácter organizativo y servicial» (FJ 2 de la STC 90/1992, de 11 de junio).

15 Ibidem. 


\section{CONCLUSIÓN}

La profusión de preceptos constitucionales dedicados a lo "cultural» confirma el importante papel que el constituyente concedió en 1978 a la Cultura. La Constitución de 1978 es la primera en nuestra historia constitucional que contiene una concepción global, no fragmentaria y dispersa, de la Cultura.

La opción por un "Estado de Cultura" es una decisión política fundamental del constituyente que aunque no ha sido recogida en el artículo 1 de la Constitución puede deducirse con facilidad del Texto constitucional (especialmente de lá claúsula del art. 149.2).

Prieto de Pedro lo ha expuesto brillantemente. El Estado de Cultura viene a completar, no a negar, el Estado social y democrático de Derecho: "La profundización de la democracia -recordemos que el Preámbulo de nuestra Constitución plantea como meta final alcanzar una "sociedad democrática avanzada" - más allá de garantizar la participación de todos los ciudadanos implica perseguir el objetivo cualitativo de hacer posible que esa participación sea más plena, más idónea, de forma especial mediante el reforzamiento de las garantías jurídicas de las instituciones que inciden en la formación y en el desarrollo de la personalidad de los ciudadanos, así como de los grupos en los que desenvuelven su existencia, es decir, de los institutos que aseguran la libertad de la cultura, su multiplicidad, su progreso y el igual acceso de todos los ciudadanos a ella. Si el Estado social llamó la atención sobre las garantías de lo económico-social en la persecución de ese objetivo de profundización de la democracia, el Estado de Cultura enfatiza la importancia cualitativa de lo cultural en su consecución. El Estado de Cultura no niega, pues, la aportación de las claúsulas de Estado democrático, Estado social y Estado de Derecho, sino que pretende situar en el corazón de ellas el valor de la cultura como radical principio humanizador de la acción del Estado ${ }^{16} "$.

En última instancia la opción por el Estado de Cultura supone asumir que como dijera Ortega la Cultura constituye el deber primario del Estado.

16 Prieto de Pedro, J. Cultura... ob. cit., pág. 223. 